\title{
School-Based Management with or without Instructional Leadership: Experience from Sweden
}

\author{
Erik Lindberg ${ }^{1} \&$ Vladimir Vanyushyn ${ }^{1}$ \\ ${ }^{1}$ USBE, Umeå University, Umeå, Sweden \\ Correspondence: Erik Lindberg, USBE, 90187 Umeå, Sweden. E-mail: Erik.Lindberg@usbe.umu.se
}

Received: March 10, 2013

Accepted: June 5, 2013 Online Published: July 12, 2013

doi:10.5539/jel.v2n3p39

URL: http://dx.doi.org/10.5539/jel.v2n3p39

\begin{abstract}
This study sets out to examine schools principals' perception of the importance of school-based management (SBM) and instructional leadership tasks and their assessment of the performance of those tasks in Swedish upper secondary schools. A review of the literature on SBM and instructional leadership results in a list of twenty one tasks grouped into administrative, firefighting, and instructional leadership. Analysis of the survey responses from 234 principals shows that $80 \%$ of administrative and $75 \%$ of firefighting tasks were seen as highly important and performed well, while $68 \%$ of instructional leadership tasks were perceived as of having lower importance and performance. Implications for school principals and policy-makers are discussed and venues for future research are outlined.
\end{abstract}

Keywords: school-based management, instructional leadership, Sweden

\section{Introduction}

Looking retrospectively at the history of education and educational reforms one could claim that it is characterized by periods of major changes and periods of minor adjustment that are more stable. During the last decade no one in US, Europe or "Down Under" have missed the reforms inspired by NPM and their influence during the last three decades. The calls for decentralization, autonomy, School-based Management (SBM), leadership, accountability and ultimately school efficiency are made from politicians and policymakers (Pont et al., 2008). The rise and diffusion of the accountability movement have now become global and have put focus on the schools, which are measured in different ways. The increasing focus is on student outcomes and to meet these demands principals have got a new decentralized role design, named School-based Management (SBM). It expanded the principal's space to maneuver by transferring the power to take decisions and actions in a wide array of policies. Having said that, one can note that are many benefits by designing the role according to the demands of a decentralized steering system, but many studies report that the consequences for principals working situation are that the role is more complex, demanding, stressful and that the financial administrative activities require so much time that, even if the principals work longer days, they cannot devote enough time for pedagogical issues. Even if the expectations of an implemented SBM role should lead to improved school efficiency, there are very few reports that show direct or indirect relationships between school-based management and increased student learning or improvements in teaching (Ayeni \& Ibukun, 2013).

However, the interest for instructional leadership occurred short after the first introduction of SBM and, during the effective school movement the 1980s, a consensus concerning the factors of it emerged. School Based Management can shortly be described as school management that focus on making the mission of the school clear, defining the goals, running and managing the instructional program and promoting a positive learning climate (Hallinger, 2001). Thirty years after the first introduction the concept is seen as an important component in the principle's role by policy makers and practitioners and recent reviews report a positive relationship regarding student learning (Leithwood, 2010; Robinson et al., 2008). Graczwski et al. (2009) report evidence that show how instructional leadership improve instruction, teacher practice and school improvement. Scholars like Goldring et al. (2008) and Leithwood et al. (2008) report there is a strong relationship between instructional leadership and student outcome confirmed by several meta-analytic literature review studies. Robinson (2010) argues that this positive relationship has been noticed by policymakers and will continue to be so and the encouragement for further development will continue. According to Hallinger (2010), the relationship between accountability and school improvement, SBM and instructional leadership is tight. The current trend shows that 
the interest is spreading according to the theory of diffusion (Rogers, 1995) and has become a growing challenge first in the Anglo-Saxon countries and then for school leaders in many countries (Gerwetz, 2003; Southworth, 2002). Hallinger (2005, p. 230) calls the escalating interest a "global tsunami".

Diffusion of innovations is a theory that seeks to explain how, why, and at what rate new ideas spread. One side of this coin is to see how ides are spread from the supply side, but on the other hand the idea has to be accepted, adopted and implemented. According Rogers (1995), the adopters can be divided into categories according to a scale. The innovators and early adopters are faster than others. More slow adopters are named followers and the category in the other end of the scale is named the laggards. According to Gallvan (2001) emphasize modern diffusion theory that primary decision of adoption often is taken at a top management level as a top down action, but when it meets local culture at a local level, the implementation process slow down. Therefore, he recommends those who want to achieve a successful adoption to focus on understanding how the local environment, close to the daily work, is motivated for the change. According to Lavdas et. al (2010) is it difficult to succeed in implementing a school reform, but given this background, the Anglo-Saxon countries can be labeled as innovators and early adopters of SBM role for the heads and complemented with instructional leadership. These countries have come so far in the implementation that they have started to evaluate the effects. According the scholarly debate and the Anglo-Saxon studies that are reported, do a combination SBM and instructional leadership facilitates school success. In this aspect, there are many countries that will follow. One of these countries that not has come as far as the Anglo-Saxon countries and can be seen as a follower is the Scandinavian country Sweden.

Experience from the Anglo- Saxon countries points out how beneficial, but difficult the combination of SBM and instructional leadership is. The complex role with many heterogeneous tasks does not always allow the heads to spend time to develop pedagogical issues which they think is important. However, this article raises the question of how these issues work in a "non-Anglo-Saxon" country, namely the Scandinavian country Sweden. Thus, the purpose of this study is to examine schools principals' perception of the importance of instructional leadership tasks and their assessment of the performance of those tasks.

This study focuses on upper secondary school. It is the last link in a more than ten year educational chain and will supply the universities and the companies with skilled people that should be successful in an international competitive environment. There is a need for more research at this level that is characterized by a more specialized and qualified knowledge and can be difficult for a principal to meet (Leightwood, 1996, 1998; Lundhal \& Olsson, in press). The heads' perceptions of how important instructional leadership is, how well it works in their schools in relation to other activities related to school-based management activities are mapped to increase knowledge that other followers can benefit from.

\section{Literature Review}

\subsection{School-Based Management and Consequences}

SBM has existed for more than three decades. In the late 70s it started to occupy the policy agenda and has shades of meaning (De Grauwe, 2005). The role characterized by School-based management has been implemented in a growing number of countries and the pattern of the diffusion process is similar to instructional leadership that started in North America and was first adopted in the English speaking countries. The evaluation is complicated because there has been a diversity of approaches and some clarification can be needed. It can be defined in somewhat different ways and includes a broad variety of dialects, but generally speaking has the common core that refers to a transfer of decision-making authority and responsibility at the level of the local school (Khattri et al. 2010; Moos, 2003; De Grauwe, 2005). The classical tension between control and uniformity held from a central perspective is challenged by SBM. It promotes on the other hand freedom, differentiation and responsiveness (Caldwell, 2005).

SBM rests on an assumption that autonomy and decentralization will enable decision-makers to better meet the diverse expectations of stakeholders (Cheng \& Mok, 2007). While the direction of all SBM reforms is the same - i.e., towards decentralization - their degree and emphasis can vary (Moos, 2008). There are a wide variety of SBM strategies, from giving schools full autonomy and authority over all educational, financial and personnel matters, to allowing schools to exercise autonomy over particular issues (Gertler et al., 2007). According to Briggs \& Wohlstetter (2003), SBM has been introduced in order to improve school accountability, student performance, and administrative efficiency, as well as to empower teachers. De Grauwe (2005) argues, on the other hand, that it been introduced for financial and managerial reasons. The role has changed from a traditionally administrative focus with activities like scheduling or discipline (Graczewski et al., 2009). Lundhal $(2002,2010)$ discusses how the principals no longer can rely on a book of paragraphs when they deal with 
different situations and that they have to rely more on their own judgment.

Smith et al. (2006) report that they spend much more time on management issues like meeting with parents or dealing with discipline and other "firefighting" activities than instructional activities, and Uline \& Tschannen-Moran (2007) report how activities regarding increasing student achievement also include improving the quality of the school-building. Whitty et al. (1998) discuss the implication of what they refer to as the "market view" of student improvement, which maintains that competition between and among schools will raise student performance. This approach has broadened the responsibilities of the principal to include not only management and instructional leadership, but to be successful in a competitive environment also marketing (Lingard et al., 2000; Ball, 1994). Dinham et al. (2011) have made an historical study of the principal's role and report that it is changing rapidly and is becoming increasingly complex and that they have got an accumulation of activities they never had before.

Studies indicate that the implementation of SBM in four Anglo-Saxon countries has had similar consequences for the role of principals, although certain differences can also be observed. A number of reports argue that SBM has increased principals' administrative and managerial workloads, while at the same time it has made it more difficult for them to successfully carry out their role as pedagogical leader (Wylie, 1996; Whitaker, 1998; Cranston, 1999; Portin, 2000; De Grauwe, 2005; Lindberg, 2013).

Leithwood \& Menzies (1998) made a review of SBM in English-speaking countries and in all of them principals reported that they devoted more time to management and less to teaching and pedagogy after the implementation of SBM. The workload for the principals in these countries has become more complex, diverse and time-consuming, with some principals reporting that they work up to 60 hours or more per week (MacBeth, 2009). Principals use expressions like "being sandwiched" to describe their situation. According to Phillips et al. (2007), the role of the school principal in England has changed radically, and the workload and long working hours have led to both stress and an imbalance between working life and private life. In particular, it is the administrative workload that has increased most significantly (Harvey \& Sheridan, 1995; Wylie, 1999; Harold et al., 2001; Cranston, 2000, Cranston et. al, 2003; Fitzgerald et al., 2006). In England, the 2005 report Follow-Up Research into the State of School Leadership and the Australian Government Department of Education, Country Background Report (2007) both conclude that the accountability pressures increased, and that they were frustrated by the demands of administrative and managerial matters and the time that they are required to devote to them.

\subsection{Instructional Leadership}

In this era influenced by New Public Management, Management By Objectives become a dominating steering devise and this makes goal and goal commitment among the school principals important (Lindberg, 2009). The concept is known for influencing performance and instructional leaders were early seen as goal oriented (Hallinger, 2005). The need for schools to respond to the emphasis on student performance created motivation to look for tools to increase performance and, according to Bumburg \& Andrews (1990), instructional leadership was central for school effectiveness and became initiated in US as a solution to lacking student performance and started during the $80 \mathrm{~s}$. When instructional leadership was introduced in the $1970 \mathrm{~s}$, it was poorly defined, but it has been a persistent idea. During the rise of instructional leadership in the 80 's a strong directive leadership was emphasized since then it has been developed further. The policymakers in US started to promote principals to implement a strong instructional leadership to increase school efficiency (Barth, 1986; Cuban, 1988). The role model was a goal-oriented, hands-on leader with expertise and charisma who liked taking the challenge working direct with the teachers to improve teaching and learning (Bamburg \& Andrews, 1990; Cuban 1984, Begley \& Cousins, 1990).

According to Blasé \& Blasé (1998) the definition of instructional leadership takes a departure in the perception that there is a mix of activities and in their study they concluded that instructional leadership is complex and demanding. Sheppard (1996) suggests that there exists both a broader and more narrow view of the definition at the same time. A narrow definition according to Murphy (1998) emphasizes leadership activities related directly to teaching and learning and a broad view focuses on all the activities the principal do related to that it contribute to student learning (Donmoyer and Wagstaff, 1990). Leithwood et al. (1999) argue that the vague and broad definition makes it difficult to know that the term means the same for everyone and therefore to accumulate knowledge. This situation makes it hard to compare empirical findings from different studies. Reitzug et al. (2008) mean that the definition of the principal has changed and scholars like Schön (1988), Pajak (1993), Gordon (1997) and a number of others in this field emphasize different dialects in the concept, but most scholars, like Hallinger (2005), see three key dimensions in the principal's leadership. The first is to ensure that the school 
has a clear mission, defining the mission which means determining the school goals by framing and communicating them. The second is to focus on managing the instructional program which includes condition, supervision, evaluating and control of the school's instructional program as well as coordinating the curriculum and monitoring student progress. The last dimension is promoting a positive learning climate and includes a variety of activities like promote personal development, create incentives for teachers or learning, high expectations and standards or to maintain high visibility and protecting instructional time. The coordination and control aim to create an "academic press" which stimulates student performance.

Hallinger (2010) have made a review of studies from three decades and found that the interest for instructional leadership remains and it has become "even more relevant 2010 than for 30 years ago" and that "few concepts have been more significant" (p. 274). However, whether SBM creates the conditions for instructional leadership puts the focus on the combination of SBM and instructional leadership. An intention behind the decentralized design of the new role is to encourage management activities of different kinds to facilitate increased local responsibilities. This draws the attention to activities regarding financial and administrative character, as well as those of a more acute problem solving and implementing activities of pedagogical character, such as instructional leadership to increase learning and student performance.

Thus, the focus of this study is mapping activities in different categories that are frequently performed by the principals. The three categories of activities are (1) financial and administration activities, (2) acute problem solving and (3) pedagogical issues for improving and maintaining quality in education, operationalized by using activities associated with instructional leadership. There has historically been a lack of a crystal clear definition of the three categories and which activities that fall under which categories (Pang 2007). In the next section we proceed to develop a set of single-item measures that relate to componential tasks within the three over-arching aspects. We further discuss the process of drawing a sample of school's principals in Sweden that will allow us to empirically assess principals' perceptions of the importance and performance of various instructional leadership tasks.

\section{Method}

\subsection{Sample and Data Collection}

In order to examine school principles' perceived importance of and efforts devoted to a range of tasks, we distributed postal questionnaires to the principals of all upper secondary schools in Sweden. The addresses were collected from the official homepage of the Swedish National Agency for Education.

To increase the response rate, the first mail-out was so timed that the principles received the questionnaire after the school instruction period was over and the final student grades had been reported. Thus, the questionnaire was distributed to respondents during the first half of June 2008. After collecting the first wave of responses, a post-card reminder was sent to non-respondents. A second questionnaire was sent out during last week of June, just before the official summer break. Finally, the third questionnaire was sent out in mid-August, after the official study period began but prior to students arriving to schools. This data collection effort was also complemented by a post-card reminder. In order to ensure the confidentiality of the respondents, the instructional leadership portion of the survey was to be returned in a separate envelope and, thus, it is not possible to match these answers with the location or school type of the respondent.

In total, out of the original sample of 780 principals, we have received 311 responses, of which 234 were usable, that is, contained no systematic missing values. This number corresponds to a response rate of $30 \%$. To assess the potential for non-response bias, we compared the first wave responses and last wave responses. We were not able to identify any statistically significant differences among the respondents on the variables in focus reported in the Table 1.

\subsection{Variables and Measures}

The variables describing what tasks the heads perform during the week, and the grouping of these tasks, were chosen after a thorough literature review. The activities related to instructional leadership are based on previous conceptualizations mainly by Hallinger (2010), but we are also influenced by Blasé \& Blasé (1998), Sheppard (1996), Murphy (1988), Donmoyer \& Wagstaff (1990). Following these conceptualizations, we have identified three broad classes of school principals' tasks: administrative tasks (which also includes financial issues), firefighting tasks which mean solving problems of a more acute character, and pedagogical tasks defined as managing instructional leadership.

Administrative tasks were captured by five items from the scholarly debate of what the new SBM role has meant for the heads, formulated as questions 1 to 5 reported in the Table 1, and these items investigate aspects that fall 
under the administrative category. The decentralized role meant that many issues of financial and administrative character became executed by the principal. This means they became in charge for basic work that included overarching budgeting issues and ensuring economic performance on a more operative levels. The principal's role also means that even if the local responsibilities for the financial issues are delegated, the principal is still held accountable in front of a higher level in the organization via formally reporting to the school board members. Finally, the local responsibility and a more complex and demanding role which also include activities regarding maintenance of the school building and IT infrastructure so they facilitate a good learning climate.

The four types of firefighting tasks were identified and resulted in the questions 6 to 9 , reported in the Table 1 . The local responsibility means that the principal is in charge for everything that is related running the school. This means that when something does not run smoothly and problems occur, the principal is in charge for solving them and many of these issues have an acute and firefighting character. Those concern handling of the disciplinary issues, interactions with parents, resolving emergent personnel problems, and handling interactions with the unions' representatives.

Table 1. Assessment of Perceived Importance and Performance of School Principals' Tasks

\begin{tabular}{|c|c|c|c|c|c|c|c|}
\hline & Tasks & Type* & $\operatorname{Imp}$ & Perf & $p$ & $\begin{array}{c}\text { Mean } \\
\text { Diff }\end{array}$ & Direction \\
\hline 1 & $\begin{array}{l}\text { To establish and monitor budgets and } \\
\text { meetings on budget. }\end{array}$ & A & 3.56 & 3.28 & 0.00 & 0.274 & $\mathrm{I}>\mathrm{P}$ \\
\hline 2 & $\begin{array}{l}\text { Taking care of other finance-related tasks and } \\
\text { meetings related to economic issues. }\end{array}$ & A & 3.42 & 3.10 & 0.00 & 0.329 & $\mathrm{I}>\mathrm{P}$ \\
\hline 3 & $\begin{array}{l}\text { management" on governance monitoring of } \\
\text { operations. }\end{array}$ & A & 3.15 & 3.46 & 0.00 & -0.304 & $\mathrm{P}>\mathrm{I}$ \\
\hline 4 & $\begin{array}{l}\text { To manage questions about the school's } \\
\text { facilities. }\end{array}$ & A & 3.36 & 3.74 & 0.00 & -0.387 & $\mathrm{P}>\mathrm{I}$ \\
\hline 5 & To manage questions about the school's IT. & A & 3.14 & 3.30 & 0.03 & -0.175 & $\mathrm{P}>\mathrm{I}$ \\
\hline 6 & $\begin{array}{l}\text { To manage contacts/relationships with } \\
\text { parents. }\end{array}$ & $\mathrm{F}$ & 3.81 & 2.84 & 0.00 & 0.949 & $\mathrm{I}>\mathrm{P}$ \\
\hline 7 & To manage student disciplinary matters. & $\mathrm{F}$ & 3.25 & 3.69 & 0.00 & -0.442 & $\mathrm{P}>\mathrm{I}$ \\
\hline 8 & To manage personnel matters. & $\mathrm{F}$ & 3.50 & 3.67 & 0.00 & -0.159 & $\mathrm{P}>\mathrm{I}$ \\
\hline 9 & To manage unions issues. & $\mathrm{F}$ & 3.78 & 3.59 & 0.00 & 0.202 & $\mathrm{I}>\mathrm{P}$ \\
\hline 10 & $\begin{array}{l}\text { Writing target document (school goals) in } \\
\text { consultation with school stakeholders. }\end{array}$ & IL & 3.24 & 3.18 & 0.33 & 0.059 & ns \\
\hline 11 & $\begin{array}{l}\text { To make teachers aware of and committed to } \\
\text { the school's goals. }\end{array}$ & IL & 3.74 & 3.08 & 0.00 & 0.716 & $\mathrm{I}>\mathrm{P}$ \\
\hline 12 & $\begin{array}{l}\text { To create a reward system that reflects the } \\
\text { school's goals }\end{array}$ & IL & 2.97 & 3.15 & 0.01 & -0.198 & $\mathrm{P}>\mathrm{I}$ \\
\hline 13 & To visit the teachers in the classrooms. & IL & 2.92 & 2.94 & 0.75 & -0.036 & ns \\
\hline 14 & $\begin{array}{l}\text { Being in and appear in operations ("mingle" } \\
\text { among pupils / staff). }\end{array}$ & IL & 3.24 & 3.32 & 0.15 & -0.081 & ns \\
\hline 15 & $\begin{array}{l}\text { To promote teachers use of effective teaching } \\
\text { and learning methods. }\end{array}$ & IL & 3.37 & 3.08 & 0.06 & 0.292 & $\mathrm{I}>\mathrm{P}$ \\
\hline 16 & $\begin{array}{l}\text { To create continuous improvement through } \\
\text { planned and regular activities. }\end{array}$ & IL & 2.77 & 3.04 & 0.00 & -0.241 & $\mathrm{P}>\mathrm{I}$ \\
\hline 17 & $\begin{array}{l}\text { To create a school culture that emphasizes } \\
\text { innovation and improvement in teaching. }\end{array}$ & IL & 2.18 & 2.08 & 0.39 & 0.111 & ns \\
\hline 18 & $\begin{array}{l}\text { To prepare, implement and monitor } \\
\text { individual performance. }\end{array}$ & IL & 2.89 & 2.90 & 0.99 & -0.005 & ns \\
\hline 19 & To plan and monitor training. & IL & 2.84 & 2.93 & 0.11 & -0.086 & ns \\
\hline 20 & $\begin{array}{l}\text { To give teachers advice on and suggestions to } \\
\text { improve their teaching. }\end{array}$ & $\mathrm{IL}$ & 3.04 & 2.55 & 0.00 & 0.484 & $\mathrm{I}>\mathrm{P}$ \\
\hline 21 & $\begin{array}{l}\text { To develop / maintain well-functioning team } \\
\text { of teachers. }\end{array}$ & IL & 2.39 & 3.00 & 0.00 & -0.619 & $\mathrm{P}>\mathrm{I}$ \\
\hline
\end{tabular}

Note. A-adminstrative task, F-firefighting task, IL-Instructional leadership task. Importance ranges from 1-unimportant to 4-very important; Performance ranges from 1-poor performance, 4- excellent performance

Finally, the twelve aspects of the instructional leadership tasks were translated in the questions 10-21, presented in the Table 1. Many of these are typically of "softer" nature and relate to principal's role in building up school 
culture and practices conducive to the pedagogical development. Among others, principal's tasks here encompass a multitude of tasks, from visiting teachers in the classroom to creating school culture that promotes innovation and improvements in the teaching activities.

The exact phrasing of all the questions is reported in the Table 1 . The respondents were asked to assess the importance of the tasks on a scale from 1- not important to 4-very important. The respondents were also required to evaluate how well the following tasks are being performed in their respective schools on a scale from 1-poor performance to 4-excellent performance. The following section will examine the results and seek to identify patterns in the principals' responses.

\section{Analysis and Results}

The key descriptives of the variables, means and standard deviations, are reported in the Table 1. The second column of the table also indicates whether the task falls into administrative (A), firefighting (F), or pedagogical (P) category. Given that the purpose of this study to examine the principals' perception of how important various aspects that school-based management mean and how well these function, we proceeded to examine whether there are differences between perceived importance and perceived performance of the tasks in questions.

Table 1 reports the mean differences between perceived importance and perceived performance of each task, and the significance of the pair-wise t-test. To aid the interpretation, the last column also reports the direction of the difference, that is, whether the tasks' performance is perceived as higher than its importance $(\mathrm{P}>\mathrm{I})$ or visa-versa $(\mathrm{I}>\mathrm{P})$. Not significant differences suggest that the importance is on par with the perceived performance, and are marked as (ns).

Overall, there appears to be a significant gap in perceptions of relative importance and relative performance of different tasks, with 15 out of 21 tasks exhibiting significant differences in pairwise tests. It should be noted that the administrative and firefighting groups of tasks exhibit generally higher perceived performance and importance, with means of over 3 on both performance and importance.

To aid in the interpretation of the results, we represent our findings in a $2 \times 2$ matrix, with performance being High/Low on the vertical axis and Importance being High/low on horizontal axis. While somewhat crude, such approach does summarize most of the information contained in the Table 1. To form High and Low categories we grouped the 21 statements on whether they are above or below total sample average assigned to performance (3.17) and importance (3.14). The resulting matrix grouping is presented in the Figure 1. 


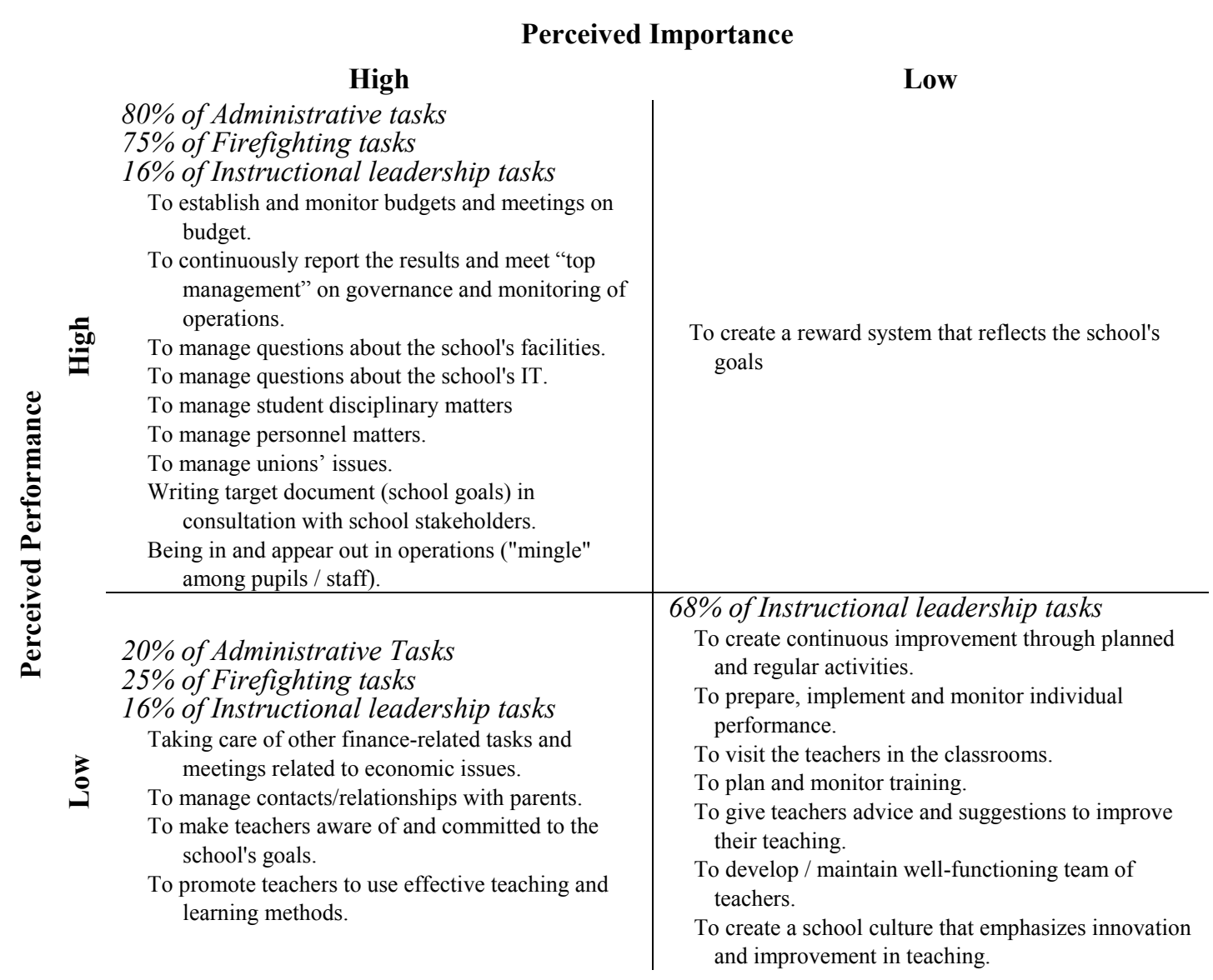

Figure 1. Perceived Importance and Performance of the School Principals' Tasks

\section{Discussion}

In this study the question is if countries like Sweden, that have been later in the adoption of SBM, have created a role where the principles does not experience that there is too much effort spent on the administrative burden and to solve acute problems in focus. Thus, we set out to map school principals' perception of how important various activities of their leadership are and to assess the relative performance in those aspects. To that end, we have identified a total of 21 tasks, grouped into administrative, firefighting and instructional leadership activities. The empirical portion of the study relies on responses from 234 school principals in Sweden. The results suggest that $80 \%$ of administrative and $75 \%$ of firefighting tasks are seen as highly important.

As such, one interesting result that the quadrant Low Importance/High Performance contains just one item that captures the development of the reward systems that reflect schools goals. As such, it appears that principals' do not overinvest efforts into tasks that they see as of a low importance. We can also find that $80 \%$ of administrative tasks and $75 \%$ of firefighting tasks ended up in High Importance/High performance category. This is well in line with the studies that suggest that the principals are overburdened with administration (Cranston 2002, 2003; Fitzgerald et. al 2006, but here the results also show that they rate the results of their efforts as relatively high. What is more unexpected is that $68 \%$ of instructional leadership tasks ended up in the Low Importance/Low performance quadrant. What that suggests is that the tasks that are directly related to schools raison d'être are sidelined.

Earlier studies of the four Anglo-Saxon countries, which invented and early adopted SBM, show how a new role, where the decentralized approach meant a much more complex role with both old and new activities, has become very time consuming. Frustrated principles reported they spent long hours at work and that too much of their activities became related to "firefighting" as well as administrative and managerial issues (MacBeth 2009, Phillips et. al 2007). At the same time the focus on instructional leadership grew and, even though there were several studies that showed how beneficial it was for student output (Hallinger 2010), the principals report too 
seldom that they have had the time for implementing and running it appropriately.

The results are in line with what previous research has shown. Scholars report on focus on the administrative workload (Harvey \& Sheridan, 1995; Cranston, 2002, 2003; Fitzgerald et al., 2006) and firefighting (Smith 2006) and the heads in this study see activities in these two areas as their most important tasks. At a more detailed level, they perceive contacts with parents and discipline issues as important in line with Smith (2006). They also rank issues with facilitates and IT high consistent with Uline \& Tschannen-Moran (2007). However, the principals see themselves as doing a good job in performing those tasks, so this do not indicate that this kind of activities cause frustration. This fact puzzles us and, although they experience doing a great job performing in these areas, it is possible that the activities more than fill their days and this can be an explanation to why they do not have much time and energy left for pedagogical issues, like in De Grauwe's (2005) study set in the Anglo-Saxon countries. The study show that $68 \%$ of the pedagogical tasks are perceived as having lower importance and the principals rated their performance on those tasks as average at bests. The result of the performance is not unexpected, but since these tasks are strongly emphasized in their role as principles, the perception of its importance discouraging for a country that is depended of a highly skilled workforce and high student outcome.

These results highlight a possible shortcoming of SBM in combination with instructional leadership. The question of what Sweden as a follower in the terminology of Rogers (1995) has learnt from other experiences in other countries becomes highlighted. Do we see over-empowered principals that are doing a great job with solving acute problems and administrative tasks, but drained by energy by fulfilling it? Does this mean that they are losing ability to focus on the pedagogical aspects of their job - something that may result in long term negative consequences for both the school teachers and the students?

Another possible explanation of the results is that they should be interpreted in the light of what Berg (1996) calls the "invisible contract". It regulates the working relationship between school leaders and teachers in such a way that there is a strict division of labour and the head is in charge of administration, management and acute problem solving, as well as keeping the teachers informed and committed to the schools mission. On the other hand, the principals leave, according to the "contract", the teachers a great autonomy to use their specialist knowledge, which the head have faith in, to transform the schools mission into the education. This could explain the heads high ranking of the item 11 (the third most important item 3,74 of 4) which "is to make sure that the teachers are aware of and feel committed to the school mission". Berg argues in his blog (on 2012-04-04) that this agreement is still associated with the situation in the school of today. In this light, reasons for the head's relatively low ranking of the importance of the factors related to instructional leadership can be explained by the fact that they see it as this responsibility are delegated to the teachers. The question if the heads see the top down approach as a tool that does not suit their local culture emerges.

The results in this study show that the combination of SBM and instructional leadership work in many ways in Sweden similar to the Anglo-Saxon countries. In both cases the heads describe that the pedagogical area should work better, but in Sweden the attitudes are towards acting in accordance with what is required for a successful instructional leadership not as expected. In many items like "to create a school culture with emphasis on innovation and improvement in teaching", "to create continuous improvement through planned and regular activities" or "to develop/ maintain teaching teams that work" the heads do not see as important.

One crucial perquisite for creating a successful combination of SBM and instructional leadership is a positive attitude of those that should manage it. This study does not uncover the reasons for why the heads do not see the activities that are connected to this approach as important. The question if they experience that the local culture does not allow a centralized top down approach or if they want to use another kind of leadership that they think work better in their local environment is left to be further studied. According to Gallvan (2001), the trouble with implementation starts in the local environment were the daily work is done. The lesson learned from this study is that followers that aim to make a successful implementing has to study to see if it suites their local context before making a final decision and not decide to implement in uncritically based on reports from Anglo-Saxon countries.

To summarize, this study shows that the combination of SBM and instructional leadership works in many ways in Sweden similar to the Anglo-Saxon countries. In both cases, the heads describe that the pedagogical area should work better, but in Sweden are the attitudes towards acting in accordance with what is required for a successful instructional leadership not as expected. In many crucial items like "to create a school culture with emphasis on innovation and improvement in teaching", "to create continuous improvement through planned and regular activities" or "to develop/ maintain teaching teams that work" the heads do not see their management as important. This indicates that the principals do not see it important to manage these activities by themselves. In 
the Swedish context is the responsibility to run the decentralized to the teachers and even if the principles do see it as highly important that they run the activities they do see pedagogical issues as important. This indicates that Swedish principals do not prefer the instructional leadership approach.

\subsection{Limitations and Venues for Future Research}

The empirical data in this study call for further research. The results are both in line with the experiences from the Anglo-Saxon countries with much focus on acute problem solving, as well as on administration. Pedagogical issues like implementing and running instructional leadership programs come in the shadow. However, this study can be extended because the reasons for why so many heads rank the importance of pedagogical issues so low as well as the performance can create a foundation for new knowledge. The results indicate that if countries like Sweden implement school-based management, it should in theory be complemented by instructional leadership. The results in this study show, however, principals with lacking motivation for implementing and running an instructional leadership program. Knowledge of the reasons for why the combination of school-based management and instructional leadership can look beneficial in theory but that local conditions can make it difficult to be successful in practice should be extended so countries that want to follow this path of implementation can benefit from other countries experiences.

One of the limitations of this study is that only heads in upper secondary schools has been studied. According to Lampart (1998) this is educational level characterized of a more specialized and qualified knowledge which not is required for the principals at lower levels in the educational system. This argument can reduce the use of these findings even if there are many similarities.

Another shortcoming of this study lies in us being unable to match the specific respondent to a particular school type. Further studies might investigate the how principles perceptions vary depending of the type of institution, e.g., public vs. private, and by the student group composition. Also, our study is exploratory in nature, and further work may look in developing constructs that measure different tasks and leadership types.

\section{Conclusions}

The main purpose of this study was to examine schools principals' perception of the importance of school-based management (SBM) and instructional leadership tasks and their assessment of the performance of those tasks in Swedish upper secondary schools. After reviewing the literature on SBM and instructional leadership, we developed a list of 21 tasks grouped into administrative, firefighting, and instructional leadership. Collecting the survey responses from 234 principals, we found out that $80 \%$ of administrative and $75 \%$ of firefighting tasks were seen as highly important and performed well, while $68 \%$ of instructional leadership tasks were perceived as of having lower importance and performance. Overall, such pattern of responses suggests that the combination of SBM and instructional leadership works in many ways in Sweden similar to the Anglo-Saxon countries. However, many principals' see instructional leadership tasks as somewhat sidelined and they do not perceive some crucial activities as important, but this hardly means they devalue their management for increasing the quality in the pedagogical area. The question remains whether the principals do not see instructional leadership as the best tool for increasing pedagogical quality and student performance emerges.

\section{References}

Ayeni, A. J., \& Ibukun, W. O. (2013). A Conceptual Model for School-Based Management Operation and Quality Assurance in Nigerian Secondary Schools. Journal of Education and Learning, 2(2), 36-44. http://dx.doi.org/10.5539/jel.v2n2p36

Ball, S. J. (1994). Education Reform: A Critical and Post-Structural Approach. Open University Press: Buckingham.

Bamburg, J., \& Andrews, R. (1990). School goals, principals and achievement. Effectivness and School Improvement, 2(3), 175-191.

Barth, R. S. (1986). The Principal and the Profession of Teaching. The Elementary School Journal, 86(4), 471-493. http://dx.doi.org/10.1086/461463

Berg, G. (2013). Personal Blog. Retrieved from http://www.miun.se/sv/Bloggportalen/forskarbloggen/ Gunnar-Berg/Dates/2011/4/Gunnar-Berg/

Berg, G. (1996). Steering, school leadership and the invisible contract. In J. Kalous, \& F. Van Wieringen (Eds.), Improving Educational Management. De Lier: Academisch Boeken Centrum.

Blasé, J., \& Blasé, J. (1998). Handbook of Instructional leadership: how reality really good principals promote teaching and learning. Thousand Oaks, CA, Cormin Press. 
Blasé, J., \& Blasé, J. (1999). Principal Instructional leadership and teacher development: Teachers perspective. Educational Administration Quarterly, 35(3), 349-378. http://dx.doi.org/10.1177/00131619921968590

Briggs, K. L., \& Wohlsetter, P. (2003). Key elements of a successful school-based management strategy. School Effectiveness and School Improvement, 14(3), 351-372. http://dx.doi.org/10.1076/sesi.14.3.351.15840

Caldwell, B. (2005). School-Based Management. Paris: IIEP-UNESCO,

Cheng, Y. C., \& Mok, M. C. (2007). School-based management and paradigm shift in education: An empirical study. The International Journal of Educational Management, 21(6), 517-542. http://dx.doi.org/10.1108/09513540710780046

Cranston, N., Ehrich, L., \& Billot, J. (2003). The secondary school principalship in Australia and New Zeeland: an investigation of changing roles. Leadership and Policy in Schools, 2(3), 159-188. http://dx.doi.org/10.1076/lpos.2.3.159.16530

Cranston, N., \& Ehrich, L. (2002). Overcoming sleeplessness: Role and workload of secondary school principals in Queensland. Leading \& Managing, 8(1), 17-35.

Cranston, N., Dwyer, J., \& Limerick, B. (2000). Making a difference? School and community practices. In D. Meadmore, B. Burnett, \& G. Tait (Eds.), Practising education: Social and cultural perspectives (pp. 99-114). Frenchs Forest, NSW: Prentice Hall Sprint Print.

Cranston, N. (1999). Teachers as leaders: A critical agenda for the new millennium. Asia-Pacific Journal of Teacher Education, 28(2), 123-131. http://dx.doi.org/10.1080/713650688

Cuban, L. (1988). Transforming frog into prince. Effective school research policy, and practice at a district level. Harvard University Press.

De Grauwe, A. (2005). Improving the quality of education through school-based management: Learning from international experiences. International Review of Education, 51(4), 269-287. http://dx.doi.org/10.1007/s11159-005-7733-1

Stephen, D., Michelle, A., Brian, C., \& Paul, W. (2011). Breakthroughs in school leadership development in $\begin{array}{lllll}\text { Australia. School Leadership \& } & \text { Management, } & 31(2), & 139-154 .\end{array}$ http://dx.doi.org/10.1080/13632434.2011.560602

Donmoyer, P., \& Wagstaff, J. G. (1990). Principals Can Be Effective Managers and Instructional Leaders. NASSP Bulletin, 74, 20-29. http://dx.doi.org/10.1177/019263659007452506

Fitzgerald, T., Gunter, H., \& Eaton, J. (2006). The Missing Link? Middle Leadership in Schools in England and New Zealand. New Zealand Journal of Educational Leadership, 21(1), 29-43.

Gallvan, M. J. (2001). Organizational adoption and assimilation of complex technological innovations., development and application of a new framework. The Database for Advances in Information Systems, 32(3), 51-58. http://dx.doi.org/10.1145/506724.506729

Gertler, P., Patrinos, H. A., \& Rubio-Codina, M. (2007). Methodological Issues in the Evaluation of School-Based Management Reforms. Unpublished report, World bank, Wasington. DC.

Gordon, A. (1997). On Being a Principal: The Rewards and Challenges of School Leadership. The Jossey-Bass Education Series: New Directions for School Leadership.

Graczewski, C., Knudson, C. J., \& Holtzman, D. J. (2009). Instructional leadership in practice: What does it look like, and what influence does it have? Journal of Education for Students Placed at Risk, 14, 72-96. http://dx.doi.org/10.1080/10824660802715460

Gewertz, C. (2003). N.Y.C. Chancellor Aims to Bolster Instructional Leadership. Education Week, 22(16), 7-12.

Goldring, E., Huff, J., Pareja, A., \& Spillane, J. (2008). Measuring principals' content knowledge of learning-centered leadership. Paper presented at the American Educational Research Association annual conference, New York.

Hallinger, P. (2010). Leadership for learning: Lessons from 40 years of empirical research. Journal of Educational Administration, 49(2), 125-142. http://dx.doi.org/10.1108/09578231111116699

Hallinger, P. (2005). Instructional Leadership and the School Principal: A Passing Fancy that Refuses to Fade Away. Leadership and Policy in School, 4(3), 221-239. http://dx.doi.org/10.1080/15700760500244793

Hallinger, P. (2001). A review of two decades of research on the principalship using the Principal Instructional 
Management Rating Scale. Paper presented at the annual meeting of the American Educational Research Association. Seattle, WA.

Harold, B., Hawksworth, L., Mansell, H., \& Thrupp, M. (2001). Self Management: The Experience of New Zealand Principals. Retreived from http//www.icponline.org/feature_articles

Harvey, M., \& Sheridan, B. (1995). Measuring the perception of the primary school deputy principal's responsibilities. Journal of Educational Administration, 33(4), 69-91. http://dx.doi.org/10.1108/09578239510092532

Khattri, N., Ling, C, \&, Jha, C. (2010). The Effects of School-Based Management in the Philippines: An Initial Assessment Using Administrative Data. World Bank Policy Research Working Paper No. 5248.

Lavdas, Kostas A., Nikos E. Papadakis, \& Yiota G. Rigopoulou. (2012). Learning Organizations and Policy Transfer in the EU: Greece's State Scholarships Foundation in a Reform-resistant Context. Journal of Education and Learning, 1(2), 95-108. http://dx.doi.org/10.5539/jel.v1n2p95

Leithwood, K., \& Menzies, T. (1998). Forms and effects of school-based management: A review. Educational Policy, 12(3), 325-347. http://dx.doi.org/10.1177/0895904898012003006

Leithwood, K., Tomlinson, D., \& Genge, M. (1996). Transformational school leadership. In Leithwood, K. (Ed.), International Handbook of Educational Leadership and Administration (pp. 785-840). Kluwer Academic Publishers: Dorrecht

Lindberg, E. (2012). The power of role design: Balancing the principals financial responsibility with the implications of stress. Educational Assessment, Evaluation and Accountability, 24, 151-171. http://dx.doi 10.1007/s11092-011-9139-x

Lindberg, E., \& Wincent. J. (2011). Goal commitment and performance: An empirical study incorporating role stress literature to reveal functional and dysfunctional influence. Journal of Applied Social Psychology, 41(11), 2634-2655. http://dx.doi.org/10.1111/j.1559-1816.2011.00837.x

Lingard, B., Mills, M., \& Hayes, D. (2000). Teachers, school reform and social justice: Challenging research and practice. The Australian Educational Researcher, 27(3), 101-115. http://dx.doi.org/10.1007/BF03219733

Lundhal, L., \& Olsson, M. (in press). Democracy lessons in market-oriented schools: The case of Swedish upper secondary education.

Lundahl, L., Erixon, A., Arreman, I., Lundström, U., \& Rönnberg, L. (2010). Setting Things Right? Swedish Upper Secondary School Reform in a 40-year Perspective. European Journal of Education, 45(1), 46-59. http://dx.doi.org/10.1111/j.1465-3435.2009.01414.x

Lundahl, L. (2002). Sweden: Decentralization, deregulation, quasi-markets - and then what? Journal of Education Policy, 17(6), 687-697. http://dx.doi.org/10.1080/0268093022000032328

MacBeth, J. (2009). Recruitment and retention of Senior School leaders: Meeting the challenge. European Educational Research, 8(3), 407-417. http://dx.doi.org/10.2304/eerj.2009.8.3.407

Moos, L (2008). School leadership for Demokratic Bildung: Fundamentalism beliefs or critical reflect. School Leadership \& Management, 28(3), 229-246. http://dx.doi.org/10.1080/13632430802145829

Moos, L. (2003) Educational leadership: Leading for/as 'Dannelse'? International Journal of Leadership in Education, 6(1), 19-33. http://dx.doi.org/10.1080/1360312022000038522

Murphy, J. (1988). Methodological, Measurement, and Conceptual Problems in the Study of Instructional Leadership. Educational Evaluation and Policy Analysis, 10(2), 117-139. http://dx.doi.org/10.2307/1163884

Pajak, E. (1993). Challenges and Achievements of American Education. Yearbook of the Association for Supervision and Curriculum Development.

Pang, S., K. (2007). The continuing professional development of principals in Hong Kong. Frontiers of Education in China, 2(4), 605-619. http://dx.doi.org/10.1007/s11516-007-0044-5

Philips, A., Sen, D., \& McNamee, R. (2007). Prevalence and causes of self-reported work-related stress in head teachers. Occupational Medicine, 57(5), 367-376. http://dx.doi.org/10.1093/occmed/kqm055

Portin, B. S. (2000). The changing urban principalship. Education and urban society, 32(4), 492-505. http://dx.doi.org/10.1177/0013124500324005 
Reitzug, U., West, D. \& Angel, R. (2008). Conceptualizing educational leadership: The voices of principals. Education and Urban Society, 40(6), 694-714.

Robinson, V. (2010). From instructional leadership to leadership capabilities: Empirical findings and methodological challenges. Leadership and Policy in Schools, 9, 1-26. http://dx.doi.org/10.1080/15700760903026748

Robinson, V., Lloyd, C., \& Rowe, K. (2008). The impact of leadership on student outcomes: An analysis of the differential effects of leadership types. Educational Administration Quarterly, 44(5), 564-588. http://dx.doi.org/10.1177/0013161X08321509

Rogers, E. (1995). Diffusion of innovations (4th ed.). New York. Free Press.

Sheppard, B. (1996). Exploring the transformational nature of instructional leadership. Alberta Journal of Educational Research, 42(4), 325-334.

Schön, D. A. (1988). Coaching reflective teaching. In P. P. Grimmett, \& G. F. Erickson (Eds.), Reflection in teacher education (pp. 19-30). New York: Teachers College Press.

Southworth, G. (2002). Instructional Leadership in Schools: Reflections and Empirical Evidence. School Leadership and Management, 22(1), 73-91. http://dx.doi.org/10.1080/13632430220143042

Smith, S. (2007). Principals and teachers perception of principals instructional leadership. Unpublished doctoral thesis dissertation. University of South Carolina: Columbia.

Uline, C., \& Tschannen-Moran, M. (2008). The walls speak: The interplay of quality facilities, school climate, and student achievement. Journal of Educational Administration, 46(3), 55-73. http://dx.doi.org/10.1108/09578230810849817

Whitaker, K. S. (1998). The changing landscape of the principalship: View from the inside. Planning and Changing, 29(3), 130-150.

Whitty, G., Power, S., \& Halpin, D. (1998). Devolution and choice in education. Philadelphia: Open University Press.

Wylie, C. (1999). Choice, responsiveness and constraint after a decade of self managing schools in New Zealand. In AARE-NZARE Conference Proceedings, Melbourne, Australia.

Wylie, C. (1996). Finessing Site-Based Management with balancing acts. Educational Leadership, 53(4), 54-60.

\section{Copyrights}

Copyright for this article is retained by the author(s), with first publication rights granted to the journal.

This is an open-access article distributed under the terms and conditions of the Creative Commons Attribution license (http://creativecommons.org/licenses/by/3.0/). 